\title{
ANALISIS SEDIMENTASI PADA BENDUNG BERINGEN SILA DESA STOWE BERANG KECAMATAN UTAN KABUPATEN SUMBAWA
}

\author{
BADARUDDIN ${ }^{1}$, TRI SATRIAWANSYAH ${ }^{2}$, FATURRAHMAN ${ }^{3}$ \\ Dosen Program Studi Teknik Sipil Fakultas Teknik Universitas Samawa Sumbawa Besar ${ }^{1,2}$ \\ Mahasiswa Program Studi Teknik Sipil Fakultas Teknik Universitas Samawa Sumbawa Besar ${ }^{3}$
}

\begin{abstract}
ABSTRAK
Bendung Beringin Sila merupakan salah satu bendung yang dibangun dengan biaya bantuan dari luar negeri yaitu Overseas Economic Cooperation Fund (OECF) - Jepang, yang berlokasi di desa Stowe Brang Kecamatan Utan Kabupaten Sumbawa yang digunakan sebagai sarana irigasi untuk mengairi areal persawahan seluas 2.400 ha. Melihat kondisi saat ini, Bendung Beringin Sila mengalami penumpukan sedimen di hulu bendung yang menutupi mercu bendung, bahkan saat banjir sekalipun sedimen dapat terlihat. Tujuan penelitian ini untuk mengetahui besarnya sedimentasi tahunan serta mengetahui besar perbandingan sedimen dasar (Bed Load) dengan sedimen melayang (Suspended Load).

Untuk menghitung besar debit aliran sungai pada Sub Daerah Aliran Sungai (DAS), digunakan persamaan dasar manning yang pengaruhi oleh data curah hujan dari satu stasiun selama 5 tahun terakhir. Kemudian diuji menggunakan metode Log Person Tipe III. Serta menghitung curah hujan dan debit banjir.Besarnya sedimentasi permukaan pada Sub Daerah Aliran Sungai (DAS) Utan, digunakan persamaan dasar yang dikenal dengan rumus Schoklitsch dan Forchemeir digunakan untuk menganalisa Sedimen Dasar (Bed Load) dan Sedimen Melayang (Suspended Load) yang masuk ke Bendung Beringin Sila.

Berdasarkan hasil analisa diperoleh besar Sedimen Dasar $\left(Q_{s D}\right)$ pada saat debit normal sebesar 635712,105 ton/tahun, dan Sedimen Melayang $\left(Q_{S M}\right)$ sebesar 1052356,320 ton/tahun, sedangkan pada saat banjir maksimum (Qr) Sedimen Dasar (Bed Load) sebesar 635712,105 ton/tahun dan Sedimen Melayang (Suspended Load) sebesar 4001918,400 ton/tahun.
\end{abstract}

Kata kunci: Sedimentasi, Aliran Sungai, Bendung, Debit Banjir

\section{PENDAHULUAN}

Air merupakan kebutuhan mutlak bagi mahluk hidup terutama bagi manusia, hewan dan tumbuh-tumbuhan, seiring dengan bertambahnya jumlah penduduk,maka penggunaan air mesti mengalami peningkatan pula.Ini merupakan sebuah kondisi yang mana diantara satu dengan yang lainnya saling melengkapi.

Kendala dalam mengembangkan pertanian di Indonesia khususnya di pulau Sumbawa diantaranya terbatasnya ketersediaan air di musim kemarau dan terjadinya luapan dimusim penghujan. Untuk menghindari hal tersebut, perlu dilakukan penanganan dini terutama di Daerah Aliran Sungai (DAS) dengan cara reboisasi,konservasi dan pembangunan bendung.

Salah satu faktor yang mempengaruh berkurangnya air pada bendung adalah adanya sedimentasi yang mengendap pada dasar bendung. Pola penyebaran sedimentasi tergantung pada topografi bendung dan daerah aliran sedimen. Endapan sedimentasi pada dasar bendung dapat menyebabkan berkurangnya volume air efektif bendung yang selanjutnya akan mempengaruhi umur operasional bendung.

Bendung Beringin Sila terletak di desa stowe brang Kecamatan Utan Kabupaten Sumbawa Nusa Tenggara Barat. Bendung Beringin sila merupakan sebuah bendung yang di bangun dengan tujuan yaitu mengairi areal irigasi seluas 2.400 ha, sejak dibangun bendung ini terjadi berbagai hal-hal sifatnya ilmiah, sehingga fungsi dan sifat bendung mengalami perubahan.Adapun perubahan yang terjadi adalah terjadinya penurunan jumlah ketersedian ataupun tampungan air dan hal itu terjadi dari tahun ketahun sebagai akibat penumpukan sedimen didasar bendung. 
Sedimen adalah pengendapan material ke dalam bendung akibat kerusakan lingkungan dan erosi yang terjadi di daerah aliran sungai (DAS), sehingga mengakibatkan pendangkalan di daerah bendung, hal ini sangat berpengaruh terhadap kinerja dan fungsi bendung.

Hingga saat ini volume sedimen yang ada didasar bendung tersebut diperkirakan mencapai ribuan meter kubik, volume sedimen itu tentu saja sangat berpengaruh terhadap kinerja dan fungsi bendung terutama pada fasilitas-fasilitas irigasi di antaranya kesulitan dalam mengoperasikan pintu dan mengganggu kecepatan air yang menuju saluran irigasi.

Oleh karena itu penulis tertarik untuk mengangkat permasalahan tersebut dan untuk memenuhi dalam menyelesaikan tugas akhir di program studi teknik sipil fakultas teknik dan informatika universitas samawa sumbawa besar dengan judul “ Analisis Sedimentasi Pada Bendung Beringin Sila Desa Stowe Brang Kecamatan Utan Kabupaten Sumbawa ".

\section{METODOLOGI}

Metode yang digunakan dalam penelitian ini adalah metode Analisa deskriptif, yaitu dengan memaparkan masalah - masalah yang ada, kemudian mengumpulkan data yang ada, disusun, dijelaskan dan akhirnya di analisa. Sedangkan untuk sumber data diproleh dari data primer dan data skunder, data primer diproleh langsung di lapangan, sedangkan data skunder di proleh dari dinas terkait dalam hal ini UPT. Pengairan Kec. Utan Kab.sumbawa.

\section{Lokasi Penelitian \\ Penelitian analisis volume sedimentasi yang terjadi pada bendungan Beringin Sila ini dilakukan di Desa setowe Berang - Kec. Utan - Kab. Sumbawa.}

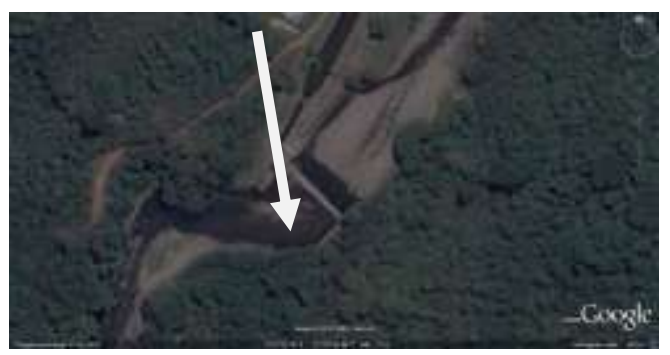

Gambar 1.lokasi penelitian (Googgle earth, 2016).

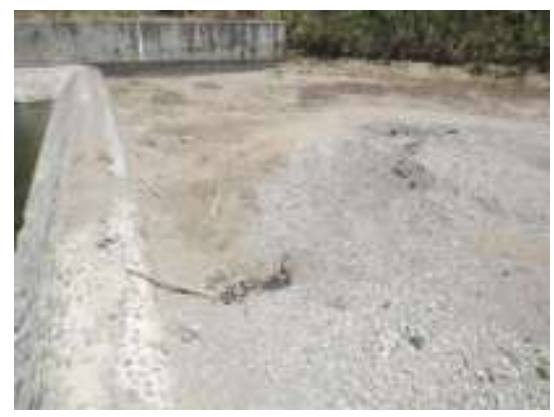

Gambar 2. Sedimentasi Bendung Beringin Sila (Dokumentasi Pribadi 2016)

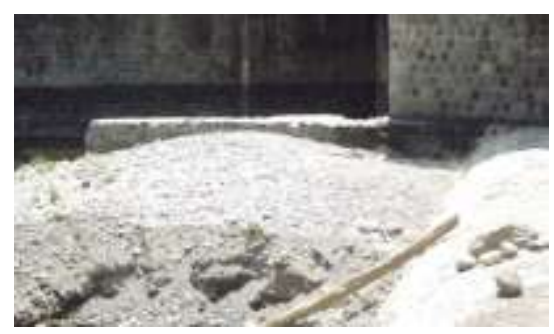

Gambar 3. Sedimentasi di pintu Bendung Beringin Sila (Dokumentasi Pribadi 2016)

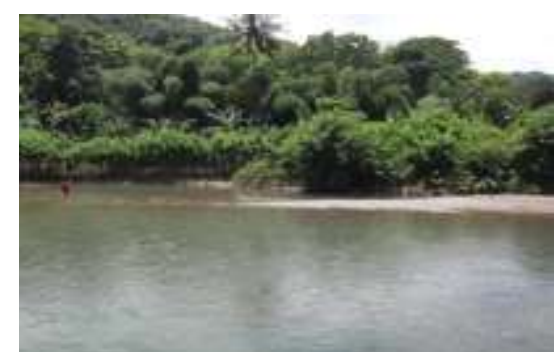

Gambar 4. kondisi sedimentasi waktu air normal ( Foto Pribadi,2016)

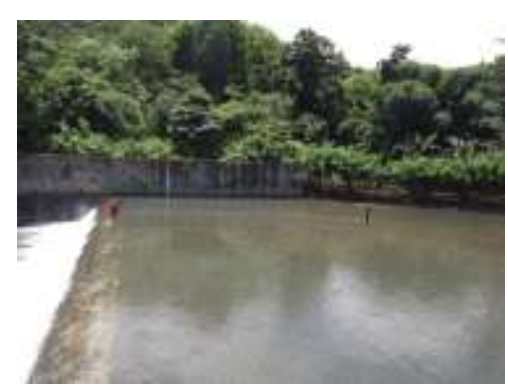

Gambar 5. kondisi sedimentasi waktu air normal ( Foto Pribadi,2016) 


\section{Jenis peneltian}

Penelitian tentang menganalisis sedimentasi pada Bendung Beringin Sila Desa Stowe Brang Kecamatan Utan ini menggunakan metode penelitian deskriptif kuantitatif. Penelitian deskriptif merupakan dasar bagi semua penelitian. Penelitian deskriptif dapat dilakukan secara kuantitatif agar dapat dilakukan analisis stastik.

\section{Survey Lapangan}

Untuk menganalisa sedimentasi dimulai dengan melakukan survey atau pengamatan secara langsung di lapangan terlebih dahulu, agar dapat diketahui aspek-aspek penting yang melatar belakangi timbulnya gagasan untuk menganalisa tersebut. Aspekaspek tersebut meliputi :

a. Pengukuran lokasi

Tahapan ini adalah berupa pengukuran lapangan meliputi pengambilan data panjang lokasi penelitian, serta tinggi ketebalan sedimentasi yang terjadi pada bendung Beringin Sila.

b. Perhitungan data hasil pengukuran

Tahapan ini adalah berupa perhitungan dari hasil pengukuran yang dilakukan di lapangan, dari hasil ini adalah dasar untuk menentukan besar sedimentasi yang terjadi pada Bendung Beringin Sila.

\section{Data Penelitian yang Diperlukan}

Data yang diperlukan untuk menyelesaikan langkah-langkah penelitiam sesuai batasan dan perumusan masalah adalah sebagai berikut :
1) Data peta topografi
2) Data curah hujan
3) Data dimensi bendung
4) Data perhitungan debit sungai di lapangan
5) Data perhitunganbesar angkutan sedimentasi

\section{Teknik Pengumpulan Data}

Teknik pengumpulan data yang di gunakan dalam studi ini adalah :
1. Metode Observasi
Metode Observasi adalah pengamatan dan pencatatan sesuatu objek dengan sistematika fenomena yang diselidiki, seperti :

1) Debit aliran sungai Untuk menghitung debit aliran sungai yaitu dengan cara :

a. Mempersiapkan alat dan bahan, seperti :

- Bola pimpong

- Patok

- Tali rafia

- Stopwatch

- Alat tulis (buku dan polpen )

b. Memasang patok 1 disebelah kiri sungai, kemudian tegak lurus kearah seberang, patok 2 .

c. Menghubungkan antara pasak nomor 1 dengan patok nomor 2menggunakan tali rafia.

d. Memastikan semua peralatan dengan kondisi baik dan siap digunakan.

e. Memulai dengan menghanyutkan bola pimpong dengan jarak 10 meter dari batas pengukuran 1 ke arah hulu sungai.

f. Menghidupkan stopwatch saat bola pimpong tepat berada dibawah tali atas daerah penampang 1.

g. Mematikan stopwatch sesaat bola pimpong telah mencapai tepat di bawah tali batas daerah penampang 2

h. Mencatat waktu menempuh jarak daerah penampang 1 ke daerah penampang $2(t)$. 
2) Dimensi Bendung

Untuk mengetahui dimensi bendung yaitu dengan cara :

a. Menyediakan roll meter

b. Mengukur lebar dan ketinggian kolam tampungan pada bendung.

3) Dimensi Sungai

Untuk mengetahui dimensi sungai yaitu dengan cara :

a. Mengukur lebar sungai

2. Metode dokumentasi

Metode dokumentasi adalah pengumpulan data dengan cara meminta data yang telah ada sebelumnya, seperti :

1) Peta topografi

Untuk mengetahui lokasi penelitian yang sebenarnya di perlukan peta kontur, peta kontur di minta di kantor Bappeda Kabupaten Sumbawa.

2) Dimensi bendung Gambar potongan bendung di peroleh dari Dinas Pekerjaan UmumKabupaten Sumbawa.

3. Metode literatur atau kepustakaan

Metode yang di gunakan dalam penelitian ini adalah metode studi literatur ( kepustakaan ). Literatur yang di maksud yaitu dari buku yang diperoleh, dari perpustakaan dan dari warnet. Data-data dan teori-teori atau temuan-temuan sebelumnya, seperti :
a) Uji Konsistensi Data Hujan
b) Analisis Distribusi
c) Distribusi Hujan
d) Analisis Hidrolika
e) Perhitungan sedimen dasar ( bad load )
f) Perhitungan sedimen melayang (suspended load)

\section{Teknik Analisis Data}

Metode yang digunakan dalam pengolahan data adalah deskriftif kualitatif yang tingkat pekerjaannya mencakup pengumpulan data, menyusun data atau mengatur data, mengolah data, atau menyajikan data dan menganalisis data agar dapat memberikan gambaran yang teratur, ringkas, dan jelas, mengenai keadaan, peristiwa atau gejala tertentu sehingga dapat di tarik atau makna tertentu.

\section{Skema Penelitian}

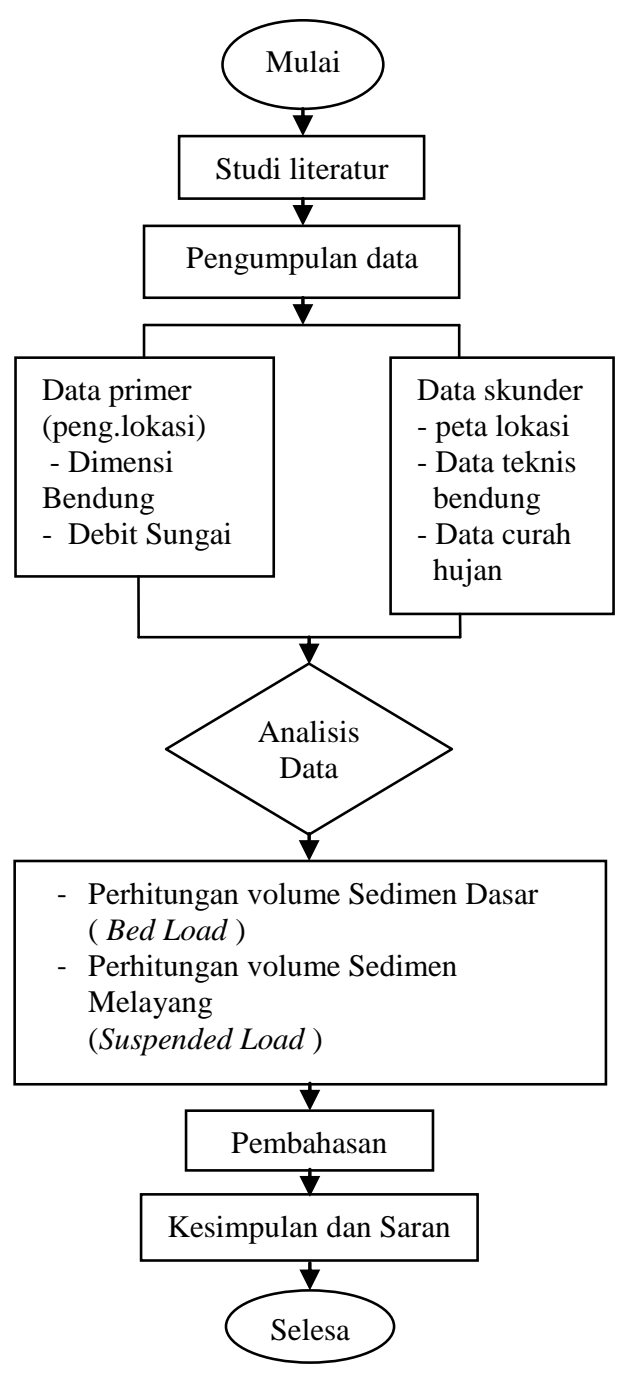

\section{HASIL PERHITUNGAN DAN PEMBAHASAN}

Untuk mengetahui besarnya angkutan sedimentasi yang terjadi pada Bendung Beringin Sila Desa Stowe Brang Kecamatan Utan Kabupaten Sumbawa, maka terlebih dahulu diperlukan data yang mencukupi untuk melakukan perhitungan dalam menetukan besar angkutan sedimentasi pada bendung pertama yang dilakukan adalah pengumpulan data. Data 
tersebut diambil dari berbagai sumber, yakni data primer dan data sekunder.

\section{Analisis Hidrologi \\ Analisis Hujan}

Data hujan yang digunakan adalah data hujan harian dari hasil pengamatan 1 stasiun hujan yang berpengaruh pada tebing yang berada di Desa Stowe brang kecamatan utan yakni stasiun hujan Kecamatan utan. Data curah hujan yang digunakan yaitu data curah hujan tahun 2011sampai dengan 2015.

Uji Konsistensi Data

Uji konsistensi dilakukan dengan menggunakan metode RAPS (Rescaled Adjusted Partial Sums).Metode ini menguji ketidak panggahan data suatu stasiun berdasarkan data dari stasiun itu sendiri dengan mendeteksi pergeseran nilai rerata (mean). Hasil uji konsistensi data curah hujan untuk stasiun Kecamatan Utan. Perhitungan uji konsistensi data curah hujan dapat dilihat dibawah ini dengan menggunakan pers. (2.1) sampai (2.5)

$$
\begin{aligned}
& \mathrm{X} \quad=\mathrm{Xi} / \mathrm{n}=5852 / 5= \\
& 1.170 \\
& \text { Max Sk** }=2,236 \\
& \text { Min Sk** }=-2,236 \\
& \mathrm{Q}=\operatorname{Max} \mathrm{Sk}^{* *}-\text { Min } \\
& \mathrm{Sk}^{* *} \\
& \begin{aligned}
&=2,236^{*}-(2,236) \\
&=4,898 \mathrm{~m}^{3} / \text { detik } \\
&=2,449 \mathrm{~m}^{3} / \text { detik } \\
& \mathrm{R} \\
& \mathrm{Q} / \mathrm{V} \mathrm{n}=0,816<\mathrm{Q} / \mathrm{V} \mathrm{n} \text { table } 95 \% \\
&=1,140 \text { ok }
\end{aligned}
\end{aligned}
$$

\begin{tabular}{|c|c|c|c|c|c|c|}
\hline No & TAHUN & $\mid$ HUJAN (Xi) & $\begin{array}{c}\mathrm{Sk}^{*}(\mathrm{X}-\mathrm{X} \\
\mathrm{X})\end{array}$ & $\left|\begin{array}{cc}D^{2} & (X i- \\
& X)^{2 / n}\end{array}\right|$ & $\begin{array}{c}\mathbf{S K}^{* *} \\
\mathbf{S}^{*} /\left(\mathrm{DY}^{2}\right)^{0,5}\end{array}$ & ABS.SK** \\
\hline 1 & 2011 & 1346 & 1346 & 362343.2 & 2.236 & 2.236 \\
\hline 2 & 2012 & 1226 & 1226 & 300615.2 & 2.236 & 2.236 \\
\hline 3 & 2013 & 1346 & 1346 & 362343.2 & 2.236 & 2.236 \\
\hline 4 & 2014 & 1012 & 1012 & 204828.8 & 2.236 & 2.236 \\
\hline 5 & 2015 & 922 & 922 & 170016.8 & 2.236 & 2.236 \\
\hline$\Sigma$ & 5 & 5852 & & \begin{tabular}{|l|l|}
1400147 \\
\end{tabular} & 2.236 & 2.236 \\
\hline
\end{tabular}

Tabel 1. Uji konsistensi data stasiun Utan
Curah Hujan Rerata Daerah

Perhitungan curah hujan rerata daerah menggunakan metode ratarata aljabar. Untuk urutan hujan harian maksimum tahunan dan hasil perhitungan hujan maksimum harian rata-rata tahunan disajikan pada rabel 4 dan 5 .

Tabel 2. Hujan harian maksimum tahunan

\begin{tabular}{|c|c|c|c|c|}
\hline \multirow{2}{*}{ TAHUN } & BULAN & TANGGAL & $\begin{array}{c}\text { STASIUN } \\
\text { UTAN }\end{array}$ & $\begin{array}{c}\text { HUJAN HARIAN } \\
\text { MAKSIMUM } \\
\text { RATA-RATA }\end{array}$ \\
\hline \multirow{2}{*}{2011} & April & 2 & 126 & 126 \\
\cline { 2 - 5 } & Mei & 2 & 72 & 72 \\
\hline \multirow{2}{*}{2012} & Januari & 12 & 60 & 60 \\
\cline { 2 - 5 } & Maret & 16 & 61 & 61 \\
\hline \multirow{2}{*}{2013} & Februari & 28 & 125 & 125 \\
\cline { 2 - 5 } & Desember & 12 & 50 & 50 \\
\hline \multirow{2}{*}{2014} & September & 18 & 80 & 80 \\
\cline { 2 - 5 } & Desember & 18 & 80 & 80 \\
\hline \multirow{2}{*}{2015} & Februari & 24 & 38 & 38 \\
\cline { 2 - 5 } & Maret & 22 & 27 & 27 \\
\hline
\end{tabular}

Tabel 3. Hujan Maksimum Harian Rata-Rata Tahunan

\begin{tabular}{|c|c|c|c|c|c|}
\hline \multirow{2}{*}{ NO } & \multirow{2}{*}{ TAHUN } & BULAN & TANGGAL & $\begin{array}{c}\text { HUJAN } \\
\text { RATA-RATA } \\
\text { HARIAN }\end{array}$ & $\begin{array}{c}\text { HUJAN } \\
\text { MAKSIMUM } \\
\text { HARIAN RATA- } \\
\text { RATA }\end{array}$ \\
\hline \multirow{2}{*}{1} & \multirow{2}{*}{2011} & April & 2 & 126 & \multirow{2}{*}{99} \\
\cline { 3 - 5 } & & Mei & 2 & 72 & \\
\hline \multirow{2}{*}{2} & \multirow{2}{*}{2012} & Januari & 12 & 60 & \multirow{2}{*}{60.5} \\
\cline { 3 - 5 } 3 & \multirow{2}{*}{2013} & Maret & 16 & 61 & \multirow{2}{*}{87.5} \\
\cline { 3 - 5 } 4 & \multirow{2}{*}{2014} & Debruari & 28 & 125 & \multirow{2}{*}{80} \\
\cline { 3 - 5 } & & Deptember & 12 & 50 & \multirow{2}{*}{32.5} \\
\hline \multirow{2}{*}{5} & \multirow{2}{*}{2015} & Februari & 24 & 30 & 38 \\
\cline { 3 - 5 } & & Maret & 12 & 27 & \multicolumn{2}{|c}{} \\
\hline
\end{tabular}

\section{Perhitungan Curah Hujan Rancangan}

Perhitungan curah hujan rancangan ini menggunakan metode Log pearson type III, metode ini paling sering digunakan dalam perhitungan curah hujan rancangan dikarenakan metode ini dapat digunakan tanpa harus memenuhi syarat dari koefisien kemencengan ( skewnes) dan koefisien kepuncakan ( kurtosis) atau dengan arti kata lain metode Log Pearson type III Cs dan Ck nya bebas.

Adapun langkah - langkah perhitungannya : 


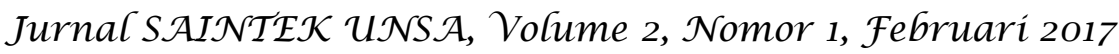

a. Mengubah data hujan harian maksimum tahunan dalam bentuk logaritma

b. Hitung nilai rata - rata logaritma

c. Hitung besarnya Standar Deviasi

d. Hitung koefisien kemencengan (Cs)

e. Hitung anti log $t$ untuk mendapatkan curah hujan rencana dengan kala ulang $T$.

Tabel 4. Perhitungan Deviasi Standar Dan Koefisien Kemencengan (Cs)

\begin{tabular}{|c|c|c|c|c|c|}
\hline No & $x_{i}$ & $\log X_{i}$ & $\begin{array}{c}\log x i-\log \\
X\end{array}$ & $(\log X i-\log X)^{2}$ & $\left(\log X_{i}-\log X\right) 2$ \\
\hline 1 & 60.5 & 1.7818 & -0.1383 & 0.0191 & -0.0026 \\
\hline 2 & 80 & 1.9031 & -0.0170 & 0.0003 & 0.0000 \\
\hline 3 & 87.5 & 1.9420 & 0.0220 & 0.0005 & 0.0000 \\
\hline 4 & 95 & 1.9777 & 0.0577 & 0.0033 & 0.0002 \\
\hline 5 & 99 & 1.9956 & 0.0756 & 0.0057 & 0.0004 \\
\hline \multicolumn{2}{|c|}{ Jumlah } & 9.6002 & 0 & 0.0289 & -0.0020 \\
\hline \multicolumn{2}{|c|}{ Rerata } & 1.9200 & & & \\
\hline \multicolumn{2}{|c|}{$S \log X$} & 0.0851 & & & \\
\hline \multicolumn{2}{|c|}{ Cs } & -0.0004 & & & \\
\hline
\end{tabular}

f. Menghitung Faktor Frekuensi $\mathrm{K}$ Berdasarkan nilai Cs, faktor frekuensi pada kala ulang dapat diperoleh dengan interpolasi faktor frekuensi distribusi Log pearson type III koefisien asimetri Cs positif. Contoh perhitungan $\mathrm{k}$ sebagai berikut, yaitu menggunakan pers. (2.6) sampai (2.10)

$k=-2,17+-\underline{0,0004-0,2 x-2,104-}$

2,178

$$
\begin{aligned}
& 0,3-0,2 \\
& =-2,326
\end{aligned}
$$

g. Menghitung curah hujan rancangan untuk kala ulang yang telah ditentukan dengan mengubah log Xt menjadi anti log dengan menggunakan persamaan 2.8 . hasil perhitungan dapat dilihat pada tabel 4.5

Tabel 5. Curah Hujan Rancangan DAS Utan

\begin{tabular}{|c|c|c|c|c|c|c|c|}
\hline $\begin{array}{c}\mathrm{Tr} \\
\text { (Tahun) }\end{array}$ & $\begin{array}{c}\text { Pr } \\
(\%)\end{array}$ & Cs & S Log X & $\log \mathrm{X}$ & $\mathrm{K}$ & $\log \mathrm{Xt}$ & $\mathrm{Xt}$ \\
\hline 2 & 50 & -0.0004 & 0.0851 & 1.9200 & -0.039 & 1.917 & 82.326 \\
\hline 5 & 20 & -0.0004 & 0.0851 & 1.9200 & 0.828 & 1.990 & 97.326 \\
\hline
\end{tabular}

Intensitas Hujan Jam - Jaman

Besar hujan rancangan untuk kala ulang 5 tahun adalah $\times 5=$
97,326 mm/jam ( dapat dilihat pada tabel 4.8 ). Untuk perhitungan dapat digunakan pers. (2.11)

untuk perhitungan waktu konsentrasi (tc) :

$\mathrm{tc}=\mathrm{to}+\mathrm{td}$

to $=5$ menit ( untuk daerah permukaan diperkeras ) $=0,083$ $\operatorname{td}=0,0195 \frac{\left[L^{0,7 y}\right.}{\mathrm{V} l}$

$\mathrm{td}=0,0195 \times\left[\mathrm{v}_{\mathrm{0}}{\frac{470^{0,002}}{}}^{, 77}\right]$

$=24,3587$ menit $=0,4059$ jam

tc $=0,083+0,4059=0.4889 \mathrm{jam}$

dengan rumus monobe dapat dicari intesitas hujan jam - jaman sebagai berikut yaitu dengan menggunakan pers.(2.11)

$$
\begin{aligned}
\mathrm{I} & =\frac{\mathrm{R} 24 \times \frac{24^{2 / 3}}{24}}{\mathrm{tc}} \\
& =\frac{97,326}{24} \times \frac{24^{2 / 3}}{0,4889} \\
& =54,439 \mathrm{~mm} / \mathrm{jam}
\end{aligned}
$$

Koefisien Aliran Permukaan (C)

Berdasarkan tabel 2.3 penggunaan lahan di Kecamatan Utan,maka koefisien pengaliran ditentukan sebagai berikut :

$$
\begin{aligned}
& \mathrm{Cm}= \frac{\mathrm{C} 1 \times \mathrm{A} 1+\mathrm{C} 2}{\mathrm{~A} 1+\mathrm{A} 2+\ldots \ldots \ldots+\mathrm{An}} 2+\ldots \ldots . \mathrm{Cn} \times \mathrm{An} \\
& \mathrm{Cm}=\quad 6,784 \times 0,5+0,35 \times 39,116+0,35 \times \\
& \frac{0,162 \ldots \ldots .}{6,784+39,116+0,162 \ldots \ldots \ldots .+0,03}
\end{aligned}
$$$$
\mathrm{Cm}=0,372
$$

Debit Banjir Maksimum

Perhitungan debit banjir maksimum metode ini menggunakan pers.(2.17)

Qr $=0,2778$. C.I . A:

Koefisien limpasan $(C)=0,372$ Intensitas hujan $\left(1^{5}\right)=54,439 \mathrm{~mm} /$

jam

Luas DAS $(\mathrm{A})=61 \mathrm{~km}^{2}$ (data bendung beringin sila)

Sehingga debit puncak dengan kala ulang 5 tahun dengan metode rasional diperoleh besar :

$$
\begin{aligned}
\mathrm{Q} 5= & 0,2778 \cdot C \cdot \mathrm{I} \cdot \mathrm{A} \\
= & 0,2778 \cdot 0,372 \cdot 0,054439 . \\
& 61000
\end{aligned}
$$




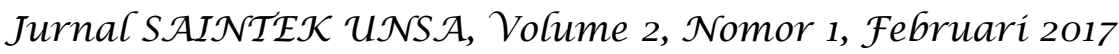

$=343,396 \mathrm{~m}^{3} / \operatorname{det}$

Perhitungan debit sungai

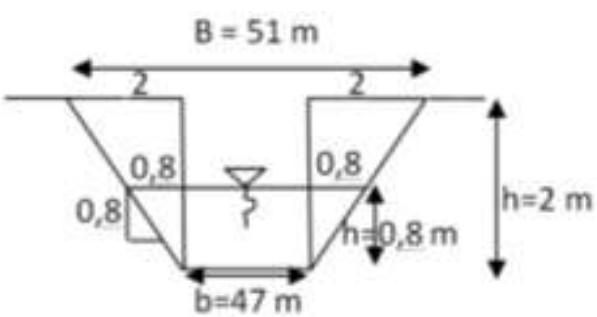

Gambar 6. Penampang Sungai

a) Lebar sungai $(x)$

$x=\frac{B+b}{2}=\frac{51+47}{2}=49$

b) Kemiringan dinding sungai ( $\mathrm{m}$ )

$\mathrm{m}=\frac{0,8}{0,8}$

$m=1$

c) Luas penampang basah ( $A$ )

$A=(b+m \cdot h) \cdot h$

$=(47+1 \cdot 0,8) \cdot 0,8$

$=38,24 \mathrm{~m}^{2}$

d) keliling basah sungai $(P)$

$\mathrm{P}=\mathrm{b}+2 \mathrm{~h}\left(\mathrm{~m}^{2}+1\right)^{0,5}$

$=47+2 \times 0,8\left(1^{2}+1\right)^{0,5}$

$=49,262 \mathrm{~m}^{2}$

e) jari - jari hidrolis ( $R$ )

$\mathrm{R}=\frac{\mathrm{A}}{\mathrm{P}}$

$=\frac{38,24}{49,262}$

$=0,7763 \mathrm{~m}$

f) Kemiringan sungai

$\mathrm{S}=\frac{\Delta h}{L}$

Dengan :

$\Delta \mathrm{h}=$ beda elevasi

$\mathrm{L}=$ Panjang

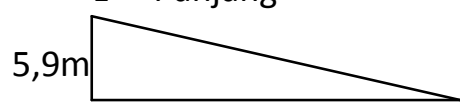

$252 m$

$$
\begin{aligned}
S & =\frac{\Delta h}{L} \\
& =\frac{5,9}{252} \\
& =0,023
\end{aligned}
$$

a) Debit aliran sungai ( $Q$ )

$$
\begin{aligned}
Q & =V \times A \\
= & \left(1 / n \times R^{2 / 3} \times S^{1 / 2}\right) \times A \\
= & \left(1 / 0,04 \times 0,7763^{2 / 3} \times 0,023^{1 / 2}\right) \times \\
& 38,24
\end{aligned}
$$

$$
\begin{aligned}
& =3,6572 \times 38,24 \\
& =139,851 \mathrm{~m}^{3} / \text { detik }
\end{aligned}
$$

\section{Analisis Sedimentasi}

Analisis Sedimen Dasar (Bed Load)

Persamaan untuk menganalisis besarnya sedimen dasar (bed load) dapat menggunakan pers. ( 2.18 ) dan pers. (2.19)

Lebar Penampang Sungai $(B)=47 \mathrm{~m}$ Kedalaman air( $h) \quad=0,80 \mathrm{~m}$ Kecepatan aliran $(\mathrm{V})=3,6572$ $\mathrm{m} /$ detik

Kemiringan sungai( $S)=0,023$

Diameter partikel sedimen(D) $=64$ $\mathrm{mm}$

Maka perkiraan besarnya sedimen dasar sungai utan dengan menggunkan rumus Schoklitsh.

$\mathrm{q}_{\mathrm{s}}=2,500 \times \mathrm{s}^{2 / 3} \cdot\left(\mathrm{q}_{\mathrm{cr}}-\mathrm{q}\right)$

$\mathrm{q}=\mathrm{h} \times \mathrm{V}$

$=0,80 \times 3,6572$

$=2,9258 \mathrm{~m}^{2} /$ detik

$\mathrm{q}_{\mathrm{cr}}=0,6 \cdot \frac{D^{3 / 2}}{S^{7 / 6}}$

$=0,6 \cdot \frac{0,064^{3 / 2}}{0,023^{7 / 6}}$

$=0,8020 \mathrm{~m}^{2} /$ detik

$\mathrm{q}_{\mathrm{s}}=2,5 \cdot \mathrm{s}^{2 / 3} \cdot\left(\mathrm{q}_{\mathrm{cr}}-\mathrm{q}\right)$

$=2,5 \cdot(0,023)^{2 / 3} \cdot(0,8020-2,9258)$

$=0,4289 \mathrm{~kg} / \mathrm{m}$.detik

$\mathrm{G}_{\mathrm{B}}=\mathrm{B} \times \mathrm{q}_{\mathrm{s}}$

$=47.0,4289$

$=2,0158 \mathrm{~kg} /$ detik

$=20,1583 \times 10^{-3}$ ton $/$ detik

Untuk satu hari

$=24.3600 .20,1583 \times 10^{-3}$

$=1741,677$ ton $/$ hari

Untuk satu tahun

$=365.1741,677$

= 635712,105 ton/tahun load)

Analisis sedimen layang ( suspended

a. Persamaan untuk menganalisis besarnya sedimen layang (suspended load) pada saat debit normal dapat menggunakan pers. ( 2.20 )

Gravitasi ( g ) $\quad=9,8 \mathrm{~m} / \mathrm{s}$

Kedalaman air $(\mathrm{h})=0,80 \mathrm{~m}$

Kemiringan $(S) \quad=0,023$ 
Debit aliran sungai $(\mathrm{Q})=$ $139,851 \mathrm{~m}^{3} /$ detik

$$
\begin{aligned}
\mathrm{U}_{*} & =\sqrt{g x h x s} \\
& =\sqrt{9,8 \cdot 0,80 \cdot 0,023} \\
& =0,0576 \mathrm{~m} / \text { detik }
\end{aligned}
$$

Maka jumlah sedimen melayang persatuan lebar yakni :

$$
\begin{aligned}
\mathrm{q}_{\mathrm{ss}} & =0,54 \cdot \frac{\mathrm{r}_{\mathrm{W}}}{{ }_{\mathrm{r}_{\mathrm{S}}-{ }_{\mathrm{W}}} \cdot \frac{\mathrm{U} *^{5}}{\mathrm{Q}}} \\
& =0,54 \cdot \frac{1}{1,25-1} \cdot \frac{0,0576^{5}}{139,851} \\
& =2,1595 \mathrm{~m}^{3} / \text { detik. }
\end{aligned}
$$

Sehingga debit total sedimen melayang persatuan lebar adalah :

$$
\begin{aligned}
& \mathrm{G}_{\mathrm{ss}}=\mathrm{q}_{\mathrm{ss} .} \mathrm{s}_{\mathrm{s} \cdot \mathrm{B}} \\
&=0,5680 \cdot 1,25 \cdot 47 \\
&=33,370 \mathrm{~kg} / \text { detik } \\
&=33,370 \cdot 10^{-3} \cdot 24 \cdot 3600 \\
&=2883,168 \text { ton } / \text { hari } \\
&=1052356,320 \text { ton } / \text { tahun }
\end{aligned}
$$

a. Menghitung debit sedimen melayang pada saat banjir dengan menggunakan pers.(2.20)

Gravitasi ( g ) $\quad=9,8 \mathrm{~m} / \mathrm{s}$ Kedalaman air $(\mathrm{h})=0,80 \mathrm{~m}$ Kemiringan (S) $\quad=0,023$ $Q$ banjir(Qr) $=343,396 \mathrm{~m}^{3} / \mathrm{s}$

$$
\begin{aligned}
\mathrm{U}_{*} & =\sqrt{g x h x s} \\
& =\sqrt{9,8 \cdot 0,80 \cdot 0,023} \\
& =0,4246 \mathrm{~m} / \text { detik }
\end{aligned}
$$

Maka jumlah sedimen melayang persatuan lebar yakni :

$$
\begin{aligned}
\mathrm{q}_{\mathrm{ss}} & =0,54 \cdot \frac{\mathrm{r}_{\mathrm{W}}}{{ }_{\mathrm{r}_{\mathrm{S}}-{ }_{\mathrm{W}}}} \frac{\mathrm{U} *^{5}}{\mathrm{Qr}} \\
& =0,54 \cdot \frac{1}{1,25-1}-\frac{0,4246^{5}}{343,396} \\
& =2,1600 \mathrm{~m}^{3} / \text { detik. }
\end{aligned}
$$

Sehingga debit total sedimen melayang persatuan lebar adalah :

$$
\begin{aligned}
\mathrm{G}_{\mathrm{ss}} & =\mathrm{q}_{\mathrm{ss}}{ }^{\mathrm{\gamma}}{ }_{\mathrm{s} . \mathrm{B}} \\
& =2,1600 \cdot 1,25 \cdot 47 \\
& =126,900 \mathrm{~kg} / \text { detik } \\
& =126,900 \cdot 10^{-3} \cdot 24 \cdot 3600 \\
& =10964,160 \text { ton } / \text { hari } \\
& =4001918,400 \text { ton } / \text { tahun }
\end{aligned}
$$

Analisis sedimen total ( Qt )

a. Analisis sedimen total pada sungai Beringin Sila pada saat normal

$$
\begin{aligned}
& \begin{aligned}
Q t & =Q_{s d}+Q_{s m} \\
& =635712,105+1052356,320 \\
& =1688068,425 \text { ton } / \text { tahun }
\end{aligned} \\
& \text { b.Analisis sedimen total pada } \\
& \text { sungai beringin sila pada saat } \\
& \text { banjir } \\
& \begin{aligned}
Q t & =Q_{s d}+Q_{r} \\
& =635712,105+4001918,40 \\
& =4637630,505 \text { ton } / \text { tahun }
\end{aligned}
\end{aligned}
$$

\section{PEMBAHASAN}

Dari pengamatan di lapangan sedimen yang terdapat disekitar areal bendung bila tidak dilakukan penanganan yang lebih serius, maka dapat menyebabkan pendangklan alur sungai di sekitar bendung serta dapat merusak fungsi bending.

Besar volume sedimen dasar (bed load) pada saat debit normal sebesar 635712,105 ton/tahun dan sedimen melayang (suspended load) sebesar 1052356,320 ton/tahun, sedangkan pada saat debit banjir maksimum besar volume sedimen dasar ( bed load ) sebesar 635712,105 ton/tahun dan sedimen melayang (suspended load) sebesar 4001918,400 ton/tahun.

Total sedimen yang terdapat di sekitar areal bendung pada saat debit normal sebesar 6325698,93ton/tahun, dari permasalahan yang ada tentang sedimentasi di daerah sekitar tubuh bendung menjadi masalah yang serius karena sebagian dari sedimentasi yang ada dapat mempengaruhi fungsi dan kinerja bendung serta mengakibatkan efektifitas tubuh bendung tidak stabil/terguling

Untuk mengatasi masalah tersebut, perlu dilakukan pengerukan dan pengangkutan sedimen dari dasar bendung, setelah dilakukan pengerukan dan pengangkutan sedimen maka bendung dapat di manfaatkan sebagai sumber irgasi persawahan oleh masyarakat sekitar secara optimal tanpa adanya endapan sedimen yang dapat mengahambat aliran air irigasi dan tidak terjadinya pendangkalan arus sungai di sekitar bendung sehingga air sungai tidah mudah meluap ke daerah sepanjang alur sungai pada musim hujan pada debit air yang tinggi. 


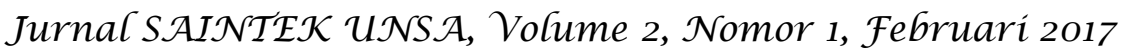

KESIMPULAN

Dari hasi analisis sedimentasi yang terjadi pada Bendung Beringin Sila mengahasilkan beberapa kesimpulan yaitu :

1. Besar volume sedimen dasar (bed load) pada debit normal sebesar 635712,105 ton/tahun dan sedimen melayang (suspended load) sebesar 1052356,320 ton/tahun dengan $Q$ total sebesar 1688068,425 ton/tahun.

2. Besar volume sedimen dasar (bed load) pada debit banjir maksimum sebesar 635712,105 ton/tahun dan sedimen melayang (suspended load) sebesar 4001918,400ton/tahun dengan Q total sebesar 4637630,505 ton/tahun.

\section{SARAN}

1. Sebaiknya pemerintah Kabupaten Sumbawa, melalui koordinasi Dinas Pekerjaan Umum Kabupaten Sumbawa untuk lebih memperhatikan masalah sedimentasi yang terjadi pada Bendung Beringi Sila seperti melakukan pengerukan dan pemeliharaan secara rutin setiap tahun, sehingga kapasitas air pada bendung dapat tetap mengairi lahan pertanian di Kecamatan Utan sesuai dengan areal rencana awal.

2. Unuk masyarakat lebih pro aktif dalam menjaga kelestarian hutan terutama disekitar radius hulu bendung.

3. Perlu ada penelitian selanjutnya sebaiknya meneruskan penelitian mengenai pengendalian sedimentasi.

\section{DAFTAR PUSTAKA}

Alimudin L, Aisyah. 2012. Pendugaan Sedimen pada DAS Mamasa Provinsi Sulawesi Barat. Skripsi. Makasar. Tanggal Akses 20 juli 2012

Asdak.C, 2007.Hidrologi dan Pengelolaan Daerah aliran sungai. Universitas Gadjah Mada : Yogyakarta
Bambang Triatmodjo, 1998, Studi Keseimbangan Air di Pulau Jawa, Forum Teknik No. 1, Tahun XX Edisi Februari.

Bambang Triatmodjo, 1998, Pengembangan Sumber Daya Air di DAS Bo-gowonto-cokroyasan, Forum Teknik Jilid 22, No. 2, Januari

Bella, Resnie 2011.“Analisis Perhitungan Muatan Sedimen (Bed Load) pada Muara Sungai Lilin Kabupaten Musi Banyuasin". Skripsi Jurusan Teknik Sipil, Universitas Sriwijaya.

Chow V.T., Maidment D.R., Mays L.W.,1988, Applied Hydrology, Mc.Graw-hill Book Company, Singapore.

Christady, Hary, 2012." Tanah Longsor dan Erosi". Gadja Mada Universitas Press, Yogyakarta.

Purnama, A, 2015. Konsentrasi Sedimen Suspensi pada Belokan $57^{\circ}$ Saluran Terbuka, Jurnal Unsa Progress. Vol.1, No.3, Oktober, Universitas Samawa, Sumbawa Besar.

Purnama, A, 2016. Analisis Distribusi Kecepatan Dan Sedimen Pada Tikungan $55^{\circ}$ Saluran Terbuka Tampang Segi Empat, Jurnal Unsa Progress. Vol.21, No.3, Juli, Universitas Samawa, Sumbawa Besar.

Rezki, Silvia, 2012, " Analisis Sedimen Pada Bendung Kakiang Kecamatan Moyo Hilir Kabupaten Sumbawa". Skripsi, universitas samawa.

Seta, A.K.Konservasi Sumber Daya Tanah dan Air Cetakan Kedua. Penerbit Kalam Mulia : Jakarta

Soemarto, C.D. 1995, Hidrologi Teknik. Penerbit Usaha Nasional: Surabaya.

Soewarno, 1995, Hidrologi, Aplikasi Metode Statistik Untuk Analisa Data, Penerbit Nova, Bandung.

Sri Harto Br.,1981, Mengenal Dasar Hidrologi Terapan, Keluarga Mahasiswa Teknik Sipil, Yogyakarta. 


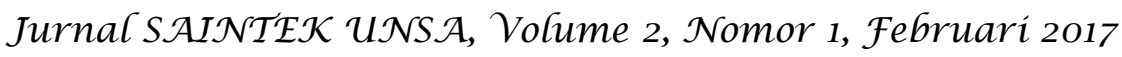

Sri Harto Br.,. 1993. Analisis Hidrologi.

Jakarta : Gramedia Pustaka Utama

Sri Harto Br., 2000, Hidrologi, Teori-

Masalah-Penyelengaraan, Nafiri

Offset, Yogyakarta.

Triatmodjo,B,2008." Hidrologi Terapan".

Beta Offset Yogyakarta, Cetakan

Pertama,Yogyakarta.http://triwahy

ukuningsih.wodpress.com/2011/08

14/soal-1-dinding-penahan-

tanah/(Tanggalakses 6 september

2016) 